\title{
Diverse system stresses: common mechanisms of chromosome fragmentation
}

\author{
JB Stevens ${ }^{1}$, BY Abdallah ${ }^{1}$, G Liu', CJ Ye ${ }^{2}$, SD Horne ${ }^{1}$, G Wang ${ }^{1}$, S Savasan ${ }^{3}$, M Shekhar ${ }^{4}$, SA Krawetz ${ }^{1}$ M Hüttemann ${ }^{1}$, \\ MA Tainsky ${ }^{4}$, GS Wu ${ }^{3}, Y X^{3}{ }^{3}, K^{2}$ Zhang $^{1}$ and HHQ Heng ${ }^{*, 1,3,4}$
}

Chromosome fragmentation (C-Frag) is a newly identified MCD (mitotic cell death), distinct from apoptosis and MC (mitotic catastrophe). As different molecular mechanisms can induce C-Frag, we hypothesize that the general mechanism of its induction is a system response to cellular stress. A clear link between C-Frag and diverse system stresses generated from an array of molecular mechanisms is shown. Centrosome amplification, which is also linked to diverse mechanisms of stress, is shown to occur in association with C-Frag. This led to a new model showing that diverse stresses induce common, MCD. Specifically, different cellular stresses target the integral chromosomal machinery, leading to system instability and triggering of MCD by C-Frag. This model of stress-induced cell death is also applicable to other types of cell death. The current study solves the previously confusing relationship between the diverse molecular mechanisms of chromosome pulverization, suggesting that incomplete C-Frag could serve as the initial event responsible for forms of genome chaos including chromothripsis. In addition, multiple cell death types are shown to coexist with C-Frag and it is more dominant than apoptosis at lower drug concentrations. Together, this study suggests that cell death is a diverse group of highly heterogeneous events that are linked to stress-induced system instability and evolutionary potential.

Cell Death and Disease (2011) 2, e178; doi:10.1038/cddis.2011.60; published online 30 June 2011

Subject Category: Experimental Medicine

Cellular stress has been implicated in many diseases, including cancer. During cancer progression, cellular stress promotes adaptive genome alterations, which increase the probability of somatic evolution. ${ }^{1}$ Multiple types of stress have been documented occurring through various molecular mechanisms, and some are linked to genome instability and apoptosis. ${ }^{2,3}$ However, cell death occurs in a number of forms, and apoptosis does not adequately represent the amount of cell death that happens in tumors in response to chemotherapy or radiation. ${ }^{4}$ Apoptosis tends to occur in response to relatively high levels of drug treatment, often higher than clinical levels, ${ }^{5}$ and the exact functions of apoptotic proteins can be contextually dependent. For example, in some cases activation of apoptotic proteins may drive proliferation. Furthermore, tumor cells often overexpress antiapoptotic proteins or lack intact cell-cycle checkpoints. ${ }^{6}$ Loss of checkpoint function allows the cells to progress to mitosis despite the presence of damaged DNA, often resulting in mitotic cell death (MCD).

Although MCD accounts for the majority of tumor cell death during treatment, its mechanism(s) is largely unknown. ${ }^{5,7-9}$ MCD appears as at least two major phenotypes: One is mitosis associated cell death, which occurs following abnormal segregation, where death takes place in $G_{1}$ following abnormal division. This form of MCD is associated with classical apoptosis, as the caspase cascade is activated following entry of multinucleated cells into $G_{1}$, and is referred to as mitotic catastrophe (MC). ${ }^{9,10}$ Another is chromosome fragmentation (C-Frag) that occurs directly during mitosis. It is readily identifiable in cytogenomic figures where degraded chromosomes are evident. $^{9}$

To illustrate the basis of C-Frag, many diverse stresses leading to $\mathrm{C}-\mathrm{Frag}$ are analyzed. A simple relationship between diverse system stresses and C-Frag is established. These stresses are shown to converge on the induction of centrosome amplification, a major component in the regulation of genome stability. Based on this relationship, the common mechanism of cell death is re-synthesized: (1) Cell death is a general response of the cellular system to stress, having a role in rebalancing the cellular system. C-Frag, a main phenotype of MCD, is achieved through an array of individual molecular mechanisms, including centrosome amplification. (2) The type of cell death that will dominate in a given sample is dependent on multiple factors, including the availability of both the targets in cells (checkpoint function, whether cells are actively dividing) and the specifics of drug treatment. (3) The types of cell death induced are heterogeneous, as shown by cytogenomic analysis. Such heterogeneity, in addition to

\footnotetext{
${ }^{1}$ The Center for Molecular Medicine and Genetics, Wayne State University School of Medicine, Detroit, MI, USA; ${ }^{2}$ Department of Internal Medicine, Wayne State University School of Medicine, Detroit, MI, USA; ${ }^{3}$ Karmanos Cancer Institute, Detroit, MI, USA and ${ }^{4}$ Department of Pathology, Wayne State University School of Medicine, Detroit, MI, USA

*Corresponding author: HHQ Heng, The Center for Molecular Medicine and Genetics, Wayne State University School of Medicine, 540 E. Canfield Street, Detroit, MI 48201, USA. Tel: + 313577 9544; Fax: + 313577 5218; E-mail: hheng@med.wayne.edu

Keywords: chromosome fragmentation; system stress; mitotic cell death; genomic instability; genome theory

Abbreviations: 17-DMAG, water-soluble geldanamycin analog; CFI, chromosome fragmentaiton index; DMF, defective mitotic figure; Dox, doxorubicin; DTT, dithiothreitol; MC, mitotic catastrophe; MCD, mitotic cell death; MMC, mitomycin-C; MTX, methotrexate; NCCA, non-clonal chromosome aberration; $\mathrm{P}(x)$, passage number; $\mathrm{Pd}(x)$, population doubling number; PCC, premature chromosome condensation; SKY, spectral karyotyping; TG, thapsigargin; TM, tunicamycin

Received 16.5.11; accepted 17.5.11; Edited by G Melino
} 
genome-level heterogeneity, ${ }^{11,12}$ explains why drug treatment can favor cancer evolution, as treatment induces stress leading to genome-mediated cancer evolution. ${ }^{1,13}$ Recent reports have detailed processes where cassettes of fragmented chromosomes have been rejoined to form highly recombined chromosomes. ${ }^{11,14,15}$ This process can affect a small number of chromosomes or nearly the entire genome, resulting in the induction of genomic instability, formation of new genome systems, and providing material for genomebased cancer evolution. Owing to the associations between C-Frag, genomic instability, disease progression, and the intervention of chemotherapies, this work underscores the potential of using C-Frag as a diagnostic tool in clinical settings.

\section{Results}

Realizing the underlying complexity of cell death processes, we have attempted to use multiple, diverse systems in order to determine the common mechanism(s) of C-Frag, which contrasts the traditional approach of using the same system to study different aspects.

PARP cleavage is associated with C-Frag. In multiple forms of cell death, DNA is degraded before stores of ATP are depleted; however, proteins such as PARP could repair the degrading DNA. ${ }^{16}$ DNA repair is avoided through the degradation of PARP by a broad range of proteases. ${ }^{16}$ Therefore, PARP cleavage was analyzed during the process of C-Frag and PARP was readily degraded (Figure 1a).

C-Frag differs from MC. To compare MC and C-Frag, a well-described model of $\mathrm{MC}$ was analyzed for C-Frag. ${ }^{17}$ Cytogenomic analysis shows that, in contrast to previous reports, the mitotic fraction of cells actually decreases, suggesting that this form of $\mathrm{MC}$ is not mitotic in origin (Figure 1b). During treatment cells became enlarged (Figure 1c) and began to die. Over the course of treatment, the frequency of C-Frag did increase, but not enough to account for the amount of cell death previously reported, showing the difference between C-Frag and MC (Figure 1b). Previous studies have focused on the G2/M based on DNA content alone. ${ }^{17}$ It is thus possible that the death observed previously was associated with cells in G2. The main morphologies observed during MC include apoptotic cells, multinucleated cells, and cells undergoing C-Frag (Figure 1d).

$\mathrm{G}_{2}$ checkpoint abrogation through loss or reduction of gene function may result in increased C-Frag. UCN-01, which ameliorates $\mathrm{G}_{2}$ checkpoint function, has a cooperative effect with many other chemotherapeutics, likely through induction of mitotic death. ${ }^{18}$ To determine whether this death is correlated with C-Frag, HCT116 cells were treated with UCN-01 and doxorubicin (Dox). Treatment resulted in the
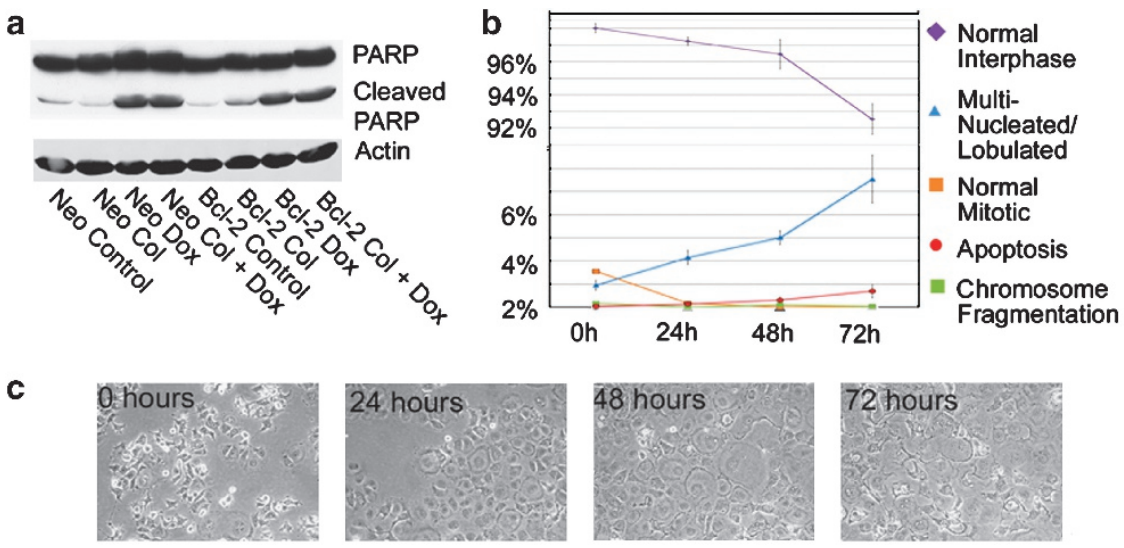

d
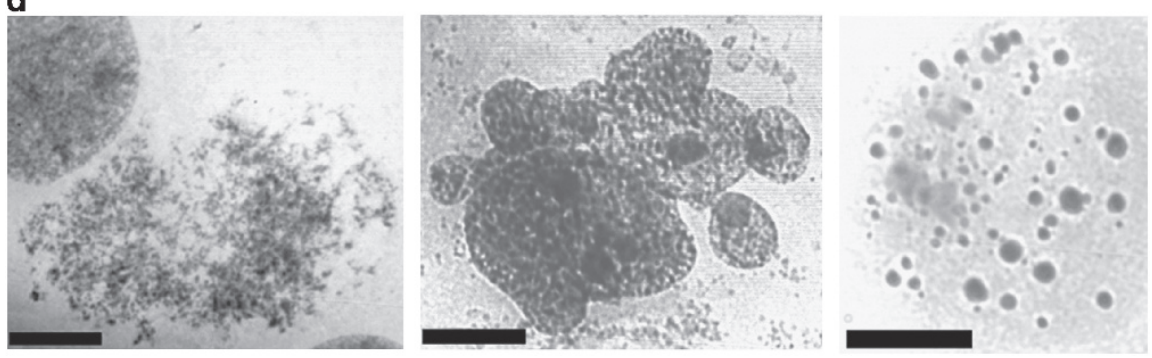

Figure 1 (a) Induction of C-Frag in H460-neo- and H460-Bcl-2-overexpressing cells by concurrent 12-h treatment with colcemid and Dox results in complete cleavage of PARP. Bcl-2-overexpressing and control cells were used to show that PARP degradation is not caused by apoptotic death in the case of C-Frag. (b-d) HCT116 14-3-3 $\sigma^{-l-}$ cells treated with $0.2 \mu \mathrm{g} / \mathrm{ml}$ Dox have been shown to die through MC. ${ }^{17}$ Seventy-two hours of treatment results in the mitotic index falling to almost 0 (orange line), whereas the percentage of multi-nucleated/multi-lobulated cells increases significantly (blue line) and the percentage of apoptotic cells rises slightly (red line) (b). During this time there is a degradation of cellular morphology as cells enlarge and die, and in agreement with previous results, by $72 \mathrm{~h}$ approximately $90 \%$ of cells died (c). ${ }^{17}$ In previous reports, the bulk of cell death was thought to be occurring in mitotic cells; however, we were unable to identify such population by cytogenomic analysis, suggesting that this death may not be attributable to mitosis. (d) Examples of C-Frag, apoptotic, and multi-lobulated/nucleated cells are shown on the left, the middle, and the right, respectively following conventional cytogenetic preparation 

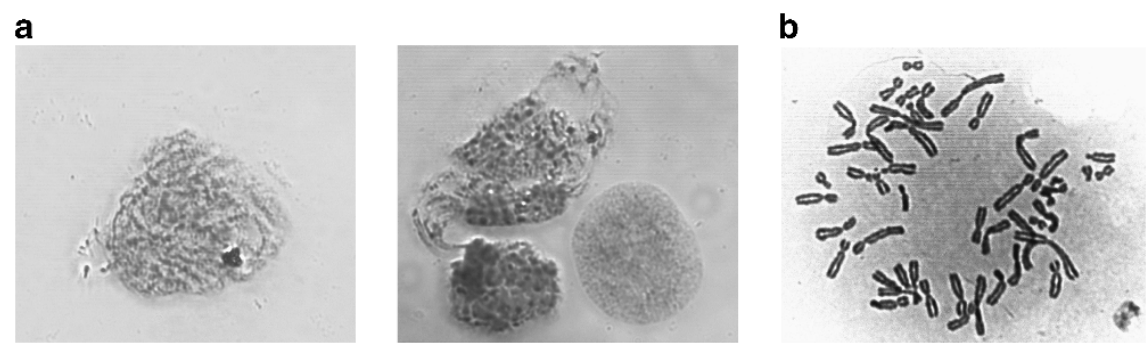

Figure 2 C-Frag is detectable in in vivo tumors prepared for cytogenomic analysis (a). Here, two examples of cells undergoing C-Frag from an untreated primary mouse tumor are shown (left and right panels). In the photo on the right the cell on the top left is an example of a defective mitotic figure (DMF) that is also undergoing C-Frag. ${ }^{12}$ The morphology of C-Frag is readily distinguishable from the normal mitotic figures of the same tumor (b)

induction of C-Frag in $36.3 \%$ of mitotic cells following $300 \mathrm{nM}$ UCN-01 and $1 \mu \mathrm{g} / \mathrm{ml}$ Dox treatment for $6 \mathrm{~h}$. By contrast, cells treated with UCN-01 or Dox alone showed a C-Frag index (CFI) of 7.2 and $9.4 \%$, respectively, showing that abnormal passage of damaged cells from $\mathrm{G}_{2}$ to mitosis can result in C-Frag.

Clinical relevance of C-Frag. C-Frag was mainly characterized using in vitro cell culture models. ${ }^{9}$ C-Frag was detected in mouse xenograft tumors without culture. C-Frag (Figure 2a) is distinguishable from normal mitotic cells (Figure $2 b$ ). We next determined the potential clinical utility of C-Frag. Tumors were analyzed from a number of cancer types, including short-term cultured solid tumors and peripheral lymphocytes from patients with hematological malignancies, and C-Frag was found to occur in all the samples (Stevens et al., unpublished data).

Linking C-Frag to various types of stresses. According to the genome theory, ${ }^{1,11-13,19,20}$ genome system instability can be induced by various stresses, including disease conditions; we thus hypothesize that system stress might represent the underlying mechanism of C-Frag. Both internal and induced stresses were examined using diverse experimental systems.

Genomic instability leads to C-Frag. C-Frag was monitored in the early and late stages of a model of spontaneous in vitro immortalization (MDAH-041) and mouse ovarian surface epithelial cell (MOSEC) model progression. ${ }^{11,13}$ In the MDAH-041 model, the spontaneous C-Frag index (CFI) mirrors overall genomic instability as measured by non-clonal chromosome aberrations (NCCAs). The CFI is 6\% at pd25, whereas once the cells stabilize at pd54 the CFI falls to $2.9 \%$ (Figure 3a). In the MOSEC model, early-stage (p9) cells have high levels of genomic instability, whereas at later stages (p91) the cells become more clonal. ${ }^{13}$ In the early stages, these cells had a moderate frequency of spontaneous C-Frag (8.8\%), whereas in the late stable stages this reduced to $0.8 \%$. Genomic instability is linked to the generation of C-Frag.

Culture stress induces C-Frag. C-Frag was first analyzed in response to temperature changes. COLO-357 cells were cultured at $37^{\circ} \mathrm{C}$ and then shifted to $42^{\circ} \mathrm{C}$ for 2 weeks before being switched back to $37^{\circ} \mathrm{C}$ (Figure $3 \mathrm{~b}$ ). When shifted from 37 to $42^{\circ} \mathrm{C}$, the cells showed an increase in CFI within $24 \mathrm{~h}$ of shifting $(P<0.01)$. The CFI stabilized at $<6 \%$ within $120 \mathrm{~h}$ of the switch. The cells stabilized at $42^{\circ} \mathrm{C}$ were switched back to $37^{\circ} \mathrm{C}$ and showed an increase in the CFI $(P=0.042)$ until it fell to $<5 \%$ within $120 \mathrm{~h}$. The observation that switching cells stabilized at $42^{\circ} \mathrm{C}$ back to the 'normal' temperature of $37^{\circ} \mathrm{C}$ induces C-Frag is significant. It suggests that any change to the current system status is a key source of stress, and that cell death is one mechanism of system adaptation.

Most cell culture uses atmospheric oxygen concentrations $(20 \%)$, whereas in vivo cells rarely experience over $3.5 \%$ $\mathrm{O}_{2}{ }^{21}$ HCT116 cells were acclimated for 5 days to $3.5 \%$ oxygen. For the first 3-4 days population doubling slowed or stopped, until cells began to once again cycle regularly. Concurrent treatment of these acclimatized cells with Dox and colcemid resulted in a CFI of $54.7 \%$, which is lower than the typically observed CFIs for HCT116 cells (nearly 100\%) with the same treatment at atmospheric oxygen. Thus, similar to other forms of programmed cell death, ${ }^{21}$ a normoxic environment suppresses C-Frag as compared with a hyperoxic environment.

ER stress induces $C$-Frag. Multiple pathways regulate various endoplasmic reticulum (ER) stress response pathways, including calcium stress, unfolded protein response, and oxidative stress. ${ }^{22}$ To determine whether these specific stress pathways could lead to C-Frag, COLO-357 cells were treated with various inducers of ER stress. Treatment with dithiothreitol (DTT), which induces the unfolded protein response by interfering with protein folding, strongly induced C-Frag (Figure 3c). Treatment with thapsigargin (TG) and tunicamycin (TM) also increased the CFI, whereas A23187 did not, instead completely blocking entry into mitosis. All four drugs induced the unfolded protein response (Figure $3 d$ ). The differential frequencies of C-Frag and apoptosis between these treatments suggest that the type of cell death depends on the availability of the targets, as with A23187 treatment there were no mitotic cells providing material for C-Frag.

Inhibition of HSP9O increases chromosome fragmentation. Heat-shock proteins (HSPs) respond to cellular stress and HSP90 specifically functions in a multitude of stress pathways. To determine whether HSP90 function may have a role in C-Frag, cells were cultured using varying concentrations of Dox that would arrest the cell-cycle and deplete mitotic cells required for C-Frag. The cells were then treated with 17-DMAG (water-soluble geldanamycin analog), a potent HSP90 inhibitor. This resulted in an increase in the frequency of C-Frag (Figure $3 \mathrm{~g}$ ), indicating that inhibition of major stress pathways predisposes cells to death. 

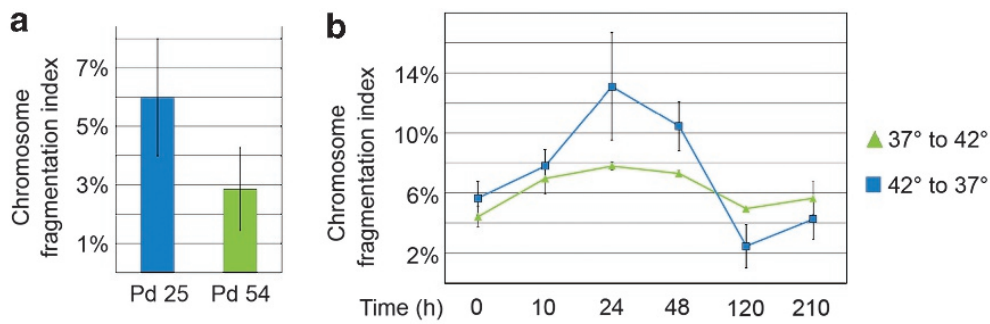

C

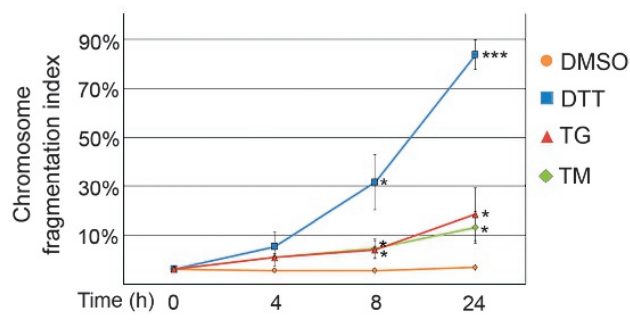

e

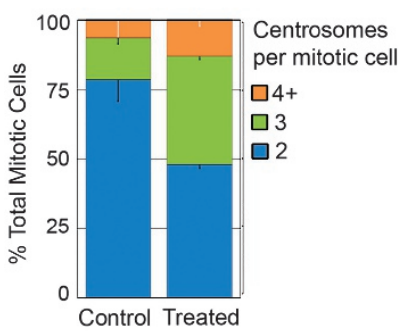

f

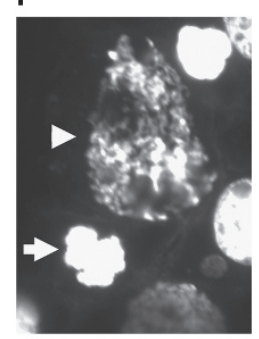

d

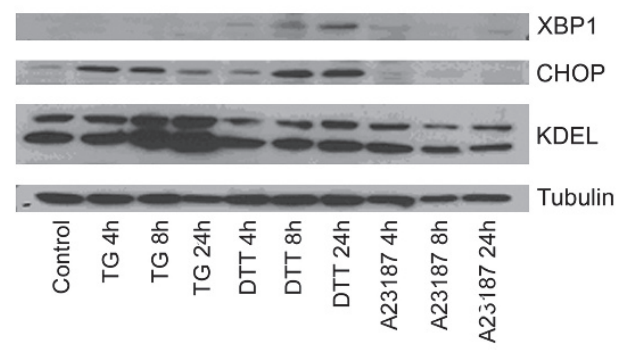

g
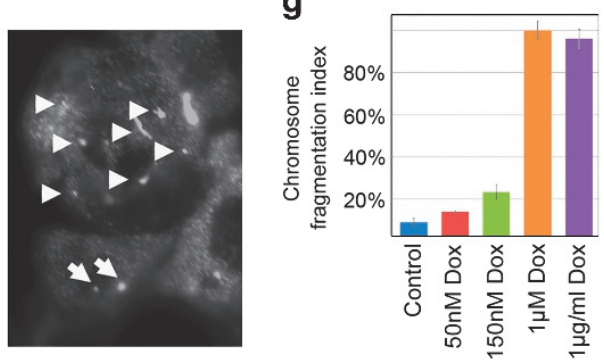

Figure 3 The effects of various stressors on C-Frag are examined $\left({ }^{\star} P<0.05,{ }^{* \star} P<0.01\right.$, $\left.{ }^{\star * \star} P<0.001\right)$ (a-C). (a) C-Frag is elevated during genomic instability (pd25) (blue bar) as compared with stable genomes (pd54) (green bar, $P<0.05$ ). (b) Increasing the culture temperature of COLO-357 cells from 37 to $42^{\circ} \mathrm{C}$ (blue line) results in a transient increase in the frequency of $\mathrm{C}$-Frag until spontaneous $\mathrm{C}$-Frag falls to $>6 \%$. Following the shift of temperature back to $37^{\circ} \mathrm{C}$ (green line) there is another corresponding increase in the $\mathrm{CFI}$, which then stabilizes at $<5 \%$. Statistical significance was calculated by comparing each time point to the 0 time point of the treatment. (c) Treatment of COLO-357 cells with specific stress inducers, including DTT (blue line), TG (red line), and TM (green line), results in varied increased C-Frag over a 24-h period. The error bars represent the standard deviation. (d) Western blot analysis of the same DTT and TG treatments show an increase in the expression of CHOP, a key protein in the ER stress response. CHOP expression increases steadily in both TG and DTT treatments from 0 to $8 \mathrm{~h}$, then falls off at $24 \mathrm{~h}$ as cells adapt to the stress. Activated XBP1 expression changes similarly in DTT-treated cells, whereas TG treatment results in little expression. Finally, there is an increase in ER proteins bearing the ER translocation sequence KDEL from 0 to $24 \mathrm{~h}$ of treatment, which is indicative of ER stress (d). Concurrent treatment with colcemid and Dox to induce C-Frag in HCT116 cells results in increased centrosome amplification (e). (f) An example of centrosome amplification (right panel, arrowheads) taking place in a cell undergoing C-Frag (left panel, arrowhead). Multiple centrosomes are detectable (arrowheads), whereas in a normal neighboring cell undergoing mitosis (left panel, arrow), only two centrosomes are present (right panel, arrows). Inhibition of HSP90 function with 17-DMAG results in increased C-Frag (g). Bars represent the CFI of cells treated with or without (control - blue bar) doxorubicin at the indicated concentration for $54 \mathrm{~h}$. After $24 \mathrm{~h}$ of treatment $100 \mathrm{nM}$ 17-DMAG was added followed by the addition of colcemid $6 \mathrm{~h}$ prior to harvest. Doxorubicin treatment at $1 \mu \mathrm{M}$ and $1 \mu \mathrm{g} / \mathrm{ml}$ (orange and purple bars respectively) would typically result in cell cycle arrest and death via apoptosis or necrosis, however 17-DMAG treatment allows cells to progress to mitosis with damage. Damaged mitotic cells are then eliminated by C-Frag. Treatment with $50 \mathrm{nM}$ (red bar) and $150 \mathrm{nM}$ (green bar) elevates the CFI, however many cells do not contain sufficient damage to induce C-Frag

\begin{abstract}
Centrosome amplification occurs in cells treated to undergo C-Frag. Centrosome amplification has been linked to temperature stress-induced $\mathrm{MCD}{ }^{23}$ Association of centrosome amplification with C-Frag may help to elucidate its mechanisms. In non-treated HCT116 cells, $21.3 \%$ of mitotic cells show three or more centrosomes (Figures $3 e$ and f). By contrast, cells treated concurrently for $12 \mathrm{~h}$ with colcemid and $1 \mu \mathrm{g} / \mathrm{ml}$ Dox showed centrosome amplification in $51.7 \%$ of mitotic cells $(P=0.021)$. Furthermore, $\mathrm{ATM}^{-1-}$ mouse cells were shown previously to exhibit centrosome amplification. ${ }^{24}$ C-Frag was found to be present in embryonic fibroblasts and lymphocytes from these mice (data not shown). Thus, there is linkage between abnormal centrosome counts and increased C-Frag.
\end{abstract}

HSP90 is a core centrosome component, suppresses centrosome instability, and is linked to MCD. ${ }^{25}$ In addition to observing increased centrosome amplification during C-Frag, it increased in association with HSP90 inhibition. Centrosome instability is also associated with genomic instability, a form of system stress that is capable of inducing C-Frag. It is thus likely that centrosome amplification is a response to stress and mechanistically links stress to MCD.

The relationship between C-Frag and other types of cell death. ER stress has been previously linked to cell death by apoptosis. Our current study also links ER stress to C-Frag; however, C-Frag and apoptosis likely use different mechanisms. ${ }^{9}$ Traditional studies focus on one type of cell 
Table 1 Nuclear features of types of cell death

\begin{tabular}{ll}
\hline Type of death & Cytogenomic features \\
\hline Apoptosis & $\begin{array}{l}\text { Nuclear blebbing resulting in grape-like } \\
\text { clusters }\end{array}$ \\
Necrosis & Nuclear shrinkage (pyknosis) \\
Autophagy & Little if any change in nuclear morphology \\
Chromosome & Degradation of condensed mitotic \\
fragmentation & chromosomes \\
\hline
\end{tabular}

a

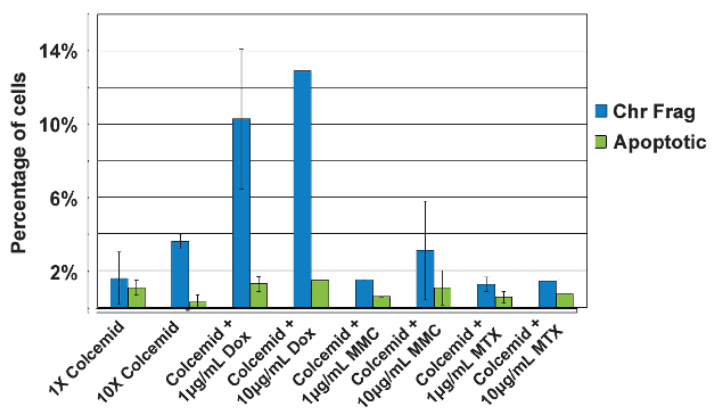

b

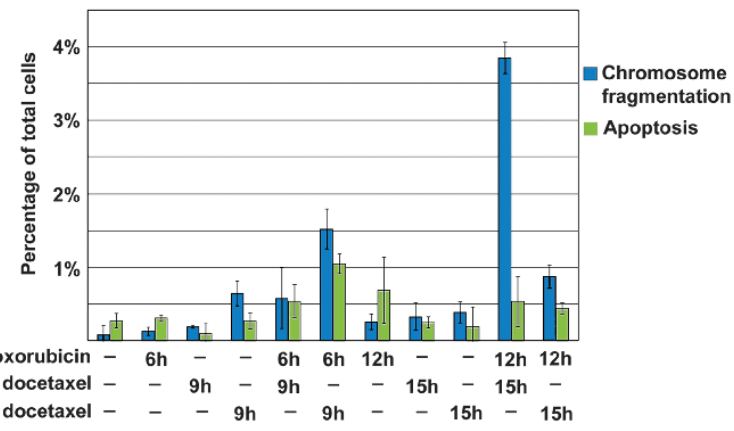

Figure 4 Different treatment combinations result in different outcomes. Concurrent treatment of HCT116 cells with colcemid and Dox, mitomycin-C (MMC), or methotrexate (MTX) result in a varied induction of cell death by apoptosis (green bars) and C-Frag (blue bars) as judged by cytogenetic examination (a). Treatment of cells with docetaxel instead of colcemid results in mitotic arrest as expected, combinatorial treatment with $1 \mu \mathrm{g} / \mathrm{ml}$ Dox and either $1 \mu \mathrm{M}$ docetaxel or $10 \mu \mathrm{M}$ docetaxel results primarily in C-Frag or apoptosis, respectively (b). As judged by previous work, some of the values for apoptotic death observed here were lower than what has been shown previously. This is likely because of differences in cytogenomic assays as compared with molecular assays to identify apoptosis such as TUNEL, which may be more sensitive

death, linking it to one specific molecular mechanism when there are likely multiple forms of cell death occurring. The above diverse response between C-Frag, apoptosis, and various drugs that induce $E R$ stress suggests an interchangeable relationship among types of cell death, prompting further study of the relationships between various mechanisms and different types of cell death (Table 1).

Heterogeneity of cell death types. HCT116 cells were treated with various combinations of drugs at various concentrations. The type of cell death incurred was scored by cytogenomic analysis where C-Frag and apoptosis are distinguishable (Table 1 and Figures $4 a$ and $b$ ). Although the occurrence of apoptosis during mitosis has not been established, a general lack of morphological descriptions of mitotic apoptosis suggests that it may not occur. It is noteworthy that apoptotic cells can be detected in populations where C-Frag is the primary form of cell death, and vice versa. For individual cells, cell death is an occurrence of opportunity, and the form of cell death is contingent on the genome status and environmental conditions.

Cell death type is influenced by dosage of drug treatment. Effects of drug concentration on death type were examined, as the required dosage for inducing apoptosis is often higher than what is clinically obtainable. ${ }^{8,26}$ For colcemid-based combinations of treatments, Dox at 10 and $1 \mu \mathrm{g} / \mathrm{ml}$ potently, but to different degrees, induces C-Frag. Mitomycin-C (MMC) treatment at $10 \mu \mathrm{g} / \mathrm{ml}$ is also capable of increasing the frequencies of C-Frag, whereas $1 \mu \mathrm{g} / \mathrm{ml} \mathrm{MMC}$, and 10 and $1 \mu \mathrm{g} / \mathrm{ml}$ methotrexate (MTX) treatment do not induce C-Frag at appreciable levels. Surprisingly, none of these treatments induced more than $2 \%$ apoptosis, based on morphological analysis suggesting that in this in vitro cancer system, C-Frag is the major form of cell death. The lack of apoptosis could be because of the length of treatment, as $6 \mathrm{~h}$ of treatment may be insufficient to induce late-stage apoptosis where apoptotic cells are identifiable by morphology.

In the case of docetaxel and Dox combinatorial treatments, a high concentration $(10 \mu \mathrm{M})$ of docetaxel combined with $1 \mu \mathrm{g} / \mathrm{ml}$ Dox increased the apoptotic response, whereas low concentrations $(1 \mu \mathrm{M})$ of docetaxel and $1 \mu \mathrm{g} / \mathrm{ml}$ Dox primarily resulted in cell death by C-Frag (Figure $4 b$ ). Although the observed levels of cell death are often less than $5 \%$, this number represents the population as a whole, the majority of which is non-mitotic. The majority of the mitotic cells are therefore undergoing C-Frag. Similarly, treatment with low concentrations of Dox and $100 \mathrm{nM}$ 17-DMAG primarily results in cell death through C-Frag; however, at increased doses of Dox apoptosis increases (Figure $3 g$ ).

C-Frag is linked to increased proteasomal activity. The H1299-v138 cell line contains a temperature-sensitive p53 mutation. ${ }^{9}$ Shifting these cells from 39 to $32^{\circ} \mathrm{C}$ results in C-Frag. ${ }^{9}$ To establish the relationship between different types of cell death, proteasome activity was measured at day 0 (restrictive temperature) until day 3 (days 1-3, permissive temperature) over which time the majority of cell death takes place. From day 0 to day 2 proteasome activity increased 1.79-fold. Proteasomal activity correlates with the induction of C-Frag $\left(r^{2}=0.768\right)$, showing that induction of C-Frag is also linked to a major mechanism of protein degradation, which is strongly associated with cell death. ${ }^{27}$

\section{Discussion}

C-Frag is a stress response. C-Frag is a general response to diverse stress. The association of C-Frag with broadranging factors suggests that the dynamics of a complex system is not likely explained by only one specific molecular mechanism. The concept presented here finally solves a mystery of the phenomenon of chromosome pulverization. 
For decades, the mechanism of chromosome pulverization has been linked to various specific causative factors such as viral vaccination, defective genes, and environmental challenges. ${ }^{28-31} \mathrm{C}$-Frag (erroneously termed premature chromosome condensation (PCC)) has been linked exclusively to single molecular mechanisms without the realization that induction of $M C D$ is a common response to stress. $^{20}$ This current study shows that the underlying general cause of this long observed phenomenon is system stress rather than a specific gene-associated phenomenon (Table 2). This conclusion also shows that multiple response pathways should be monitored in other apoptosis and molecular pathway research.

The stress-C-Frag link is significant. Stress is a major driver of genomic instability-mediated cancer evolution. ${ }^{1}$ Genome change occurs as an adaptive response to stress, increasing population diversity, the probability of survival, and potentially the acquisition of new features essential for cancer progression and drug resistance. Recently, examples of extreme genome change (genome chaos) within tumors have been reported, where multiple intra- and inter-region arrangements of chromosomes occur. ${ }^{11,14,15}$ It has been suggested that these events are the result of local chromosome shattering, ${ }^{14,15}$ although C-Frag could function as a necessary step. C-Frag has been shown to occur in one or a small number of chromosomes, ${ }^{9}$ which reconciles why only a limited number of chromosomes can be involved in cases of genome chaos. We have also observed genome chaos in multiple cell lines in

Table 2 Diverse mechanisms of C-Frag

\begin{tabular}{|c|c|}
\hline & References \\
\hline \multicolumn{2}{|l|}{ Specific mechanism of C-Frag } \\
\hline Caffeine uncoupling of the cell cycle & 40 \\
\hline Chromosome-localized UV damage & 30 \\
\hline Loss of ATM function & Current study \\
\hline Loss of ATR function & 28 \\
\hline Loss of p53 function & 29 \\
\hline Measles vaccination & 41 \\
\hline \multicolumn{2}{|l|}{ Stresses } \\
\hline Calcium & Current study \\
\hline Genomic instability & Current study \\
\hline HSP inhibition & Current study; 23 \\
\hline Oxidative & Current study \\
\hline Temperature change & Current study; 23, 31 \\
\hline Unfolded protein response & Current study \\
\hline \multicolumn{2}{|l|}{ Drugs } \\
\hline Arsenic trioxide & 23,31 \\
\hline Cytosine arabinoside & Current study \\
\hline Colcemid & 9 \\
\hline Docetaxel & Current study \\
\hline Doxorubicin & 9 \\
\hline Methotrexate & 9 \\
\hline Mitomycin-C & Current study \\
\hline \multicolumn{2}{|l|}{ Pathological conditions } \\
\hline Breast cancer & Current study \\
\hline Brain malignancies & Current study \\
\hline Hematological malignancies & Current study \\
\hline Lipoma & Current study \\
\hline Leukocytosis & Current study \\
\hline \multicolumn{2}{|l|}{ Mitotic components } \\
\hline Centrosome amplification & Current study \\
\hline
\end{tabular}

response to stress (Heng et al., unpublished results). As C-Frag is linked to stress, it is likely that these two events occur together.

C-Frag and centrosome amplification. As C-Frag occurs at mitosis, it is ideal to search for the mechanism leading to it within this time window. Centrosome amplification often results in multi-polar divisions, which can cause aneuploidy or can result in cell death. ${ }^{32}$ Heat shock or inhibition of HSP activity can induce MCD consequent to centrosome amplification. $^{23,31,33}$ HSP90 induction can be linked to broad stressors such as temperature shift and chemotherapeutics, as it is a core component of the centrosome that functions in a number of pathways, including the Chk1 pathway, which has a central role in the $G_{2}$ checkpoint. Ablation of HSP90 function increases the mitotic index and cell death during mitosis, largely by C-Frag, while correlating with increased centrosome amplification, suggesting a direct link between stress, centrosome amplification, and C-Frag. Furthermore, centrosome amplification has also been linked to wound healing, development of polyploid liver cells, genomic instability, and cancer. ${ }^{32}$ These responses can also be linked to C-Frag; thus, we conclude that C-Frag simply represents one of the main phenotypes of cells that have undergone 'cell death occurring during metaphase'. 9,34

We now propose a general model of C-Frag. Various cellular stresses can act on the mitotic machinery, such as the centrosome, and abnormal function of mitotic systems leads to C-Frag. In other words, centrosome amplification-induced mitotic failure leads to a C-Frag phenotype. As centrosomes represent major parts of the mitotic machinery, we anticipate that other important components of mitosis could also be responsible for subtypes of cell death. ${ }^{13}$ Inhibition of HSP90 reinforces these results as HSP90 has a pivotal role in centrosome stability, and its inhibition leads to increased C-Frag.

Potential diagnostic and prognostic uses of C-Frag. One problem with the use of apoptosis in disease treatment has been the observation that drug concentrations that often induce apoptosis in experimental systems do not seem to induce apoptosis in clinical settings, unless much higher concentrations are used. ${ }^{8}$ Our study shows that C-Frag can account for a portion of this disparity. Another important finding is the link between elevated C-Frag frequency and various disease conditions. C-Frag was shown to occur broadly across many types of tumors, underscoring that C-Frag is not a cell line- or gene-specific phenomenon, but rather a general response that is influenced by pathological stress to eliminate cells and maintain system stability. Further clinical investigation is needed to link elevated C-Frag to specific clinical conditions.

Induction of a specific type of cell death is largely dependent on convenience. Our data suggest that cell death is a highly complex process, and multiple forms of cell death result from a simple response to overwhelming stress(es). Whenever a population of cells is stressed sufficiently to induce death, it is likely that more than one type of cell death will be induced owing to the heterogeneous 

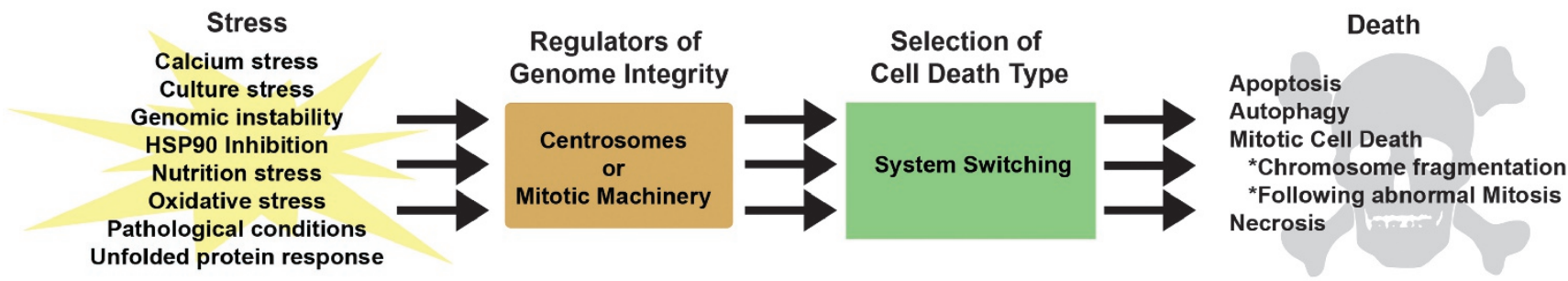

Figure 5 A proposed model illustrating the relationship between stress and the induction of various types of cell death. When a cell faces a given stress that is strong enough to induce death, multiple factors influence the selection of the specific pathways of cell death and depend on the availability of targets (mitotic or interphase cells) and/or the availability of certain pathways

means of eliminating unwanted cells. One specific form of cell death may dominate in specific instances, although subpopulations will likely undergo other terminal fates. The cell death type is highly dependent on multiple factors, including the original cell population, the type and amount of stress incurred, and the availability of targets. For instance, cancer cells are highly mitotic as compared with normal somatic cells, making mitotic cells an increasingly likely target. Unfortunately, common molecular methods such as western blotting only identify changes in an admixture of cells, but do not show variation on the single-cell level. Echoing other reports, our results showing cell death heterogeneity underscore the importance of individual cellbased analyses. ${ }^{1,8,12,35}$

Following the demonstration that the different tested stressors can induce C-Frag, it was determined that system stress represents the general mechanisms of C-Frag. The approach here differs from traditional approaches where a specific molecular pathway is identified in order to study a mechanism. However, for any given complex system, general mechanisms can be understood using the synthesis of the large number of specific mechanisms. ${ }^{1,12}$ Further synthesis led us to conclude that stress can induce all types of cell death and that stress is not specific for C-Frag. Such a conclusion complements the traditional approaches of cell death research that focus on specific molecular pathways.

To illustrate the general mechanism of cell death, we present a model suggesting a link between diverse molecular mechanisms, maintenance of genome integrity, system stress, and various types of cell death (Figure 5). This is similar to the relationship between the evolutionary mechanism of cancer and all individual molecular mechanisms. ${ }^{1,19}$ All individual molecular mechanisms can be linked to system stress in a stochastic manner. The relationship above illustrated between system stress, C-Frag, cell death, and genome alteration shows a portion of the complex means for maintaining genome stability and yet creating new genomes, which fits well within the system biology concept where system dynamics and stability can be achieved through vastly different individual molecular mechanisms. Knowing that various types of cell death can be induced by stress and coexist within heterogeneous cell populations, it is not surprising to identify the association between C-Frag and other forms of cell death. It is also possible that C-Frag can be linked to apoptosis or/and autophagy under certain conditions in terms of specific molecular pathways. However, C-Frag represents an independent form of MCD.
It should be pointed out that certain types of cell death tend to dominate in a given analysis. This is because of system complexity and high levels of cellular heterogeneity affecting cell death selection, and may help explain many of the inconsistencies of MCD. For instance, in some cases it has been shown contrastingly to be both caspase-dependent and -independent. ${ }^{9,31,36,37}$ It is quite possible that C-Frag and other subtypes of MCD coexist, and some subtypes can be linked to caspase activity. In our system, we have monitored a defined window of mitosis based on cytogenomic analysis, reducing the chance of including other types of cell death when scoring C-Frag. Moreover, the different systems examined show different pathways that can all lead to MCD. Finally, C-Frag represents a powerful means to create a new system during crises stages of somatic evolution. ${ }^{38}$

\section{Materials and Methods}

Cell culture. Cell lines were grown in RPMI-1640 (Hyclone, South Logan, UT, USA) media supplemented with $10 \%$ fetal bovine serum (FBS) (Hyclone) in $5 \% \mathrm{CO}_{2}$

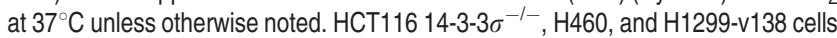
were grown with $400 \mu \mathrm{g} / \mathrm{ml}$ G418 (Fisher Scientific, Pittsburgh, PA, USA). The cell lines used in the following experiments were chosen because of their genetic manipulations. The cell lines that have not been modified were selected as they are not abnormally prone or resistant to C-Frag. Their identity was confirmed by spectral karyotyping within 6 months of use (Supplementary Table S1). The HCT116, H1299-v138, and COLO-357 cell lines were provided by Drs. Bert Vogelstein, Yi Sun, and Anton Goustin, respectively.

Isolation of cells from mouse tumors. Following resection, tumors were minced finely in PBS. Visible chunks of tumor were then digested in a trypsin solution (Hyclone) and drawn through a 25G needle until chunks were separated. The trypsin was then quenched with FBS and the two portions of the cells were mixed back together and forced through a $30-\mu \mathrm{m}$ nylon screen to remove any remaining clumps.

Chromosome preparation from cell lines, cultured lymphocytes, and solid tumors. Cytogenomic preparation performed as described by Ye et al. ${ }^{13}$ Briefly, cells were harvested, pelleted, suspended in $0.4 \% \mathrm{KCl}$ for $20 \mathrm{~min}$ at $37^{\circ} \mathrm{C}$, fixed in $3: 1$ methanol:acetic acid, and dropped onto ice-cold glass slides. The slides were then stained for $15 \mathrm{~min}$ at room temperature in $2 \%$ Giemsa solution.

Slide scoring. Slides were scored for C-Frag as described previously; ${ }^{9}$ briefly, mitotic figures were observed and cells with chromosomal degradation consistent to what was previously scored as C-Frag were counted. ${ }^{9}$ For treatments where the CFI was shown, only mitotic cells were scored. CFI was calculated by dividing the number of cells undergoing C-Frag by the total number of mitotic cells counted.

Western blotting. Western blotting analysis was performed as described by $\mathrm{Xu}$ et $\mathrm{al}^{39} .^{39}$ To determine expression levels of CHOP, KDEL, XBP1 and $\alpha$-tubulin total cell lysates were prepared from treated COLO-357 cells using NP-40 lysis buffer ( $1 \%$ NP-40, $50 \mathrm{mM}$ Tris-HCL pH 7.5, $150 \mathrm{mM} \mathrm{NaCl}, 0.05 \%$ SDS, $0.5 \mathrm{mM} \mathrm{Na}$ vanadate, $100 \mathrm{mM} \mathrm{NaF}, 50 \mathrm{mM} \beta$-glycerophosphate, and $1 \mathrm{mM}$ 
phenylmethylsulfonyl fluoride) supplemented with protease inhibitors (EDTA-free Complete Mini, Roche, San Francisco, CA, USA). Denatured proteins were separated by SDS-PAGE on 10\% Tris-glycine polyacrylamide gels and transferred to a $0.45 \mathrm{~mm}$ PVDF membrane (GE Healthcare, Waukesha, WI, USA). Detection was performed with CHOP (Santa Cruz Biotech, Santa Cruz, CA, USA), KDEL (Enzo Life Sciences, Plymouth Meeting, PA, USA), XBP1 (Santa Cruz Biotech) and $\alpha$-tubulin (Sigma-Aldrich, St Louis, MO, USA) antibodies at manufacturers suggested concentrations. HRP conjugated Rabbit TrueBlot secondary antibody (eBioscience, San Diego, CA, USA) was used for secondary diction as is avoids detecting the Ig heavy and light chains from denatured samples. Bound antibody was detected using enhanced chemiluminescence $(E C L)$ reagent or ECL Plus reagent (GE Healthcare) according to the manufacturer's protocol.

Induction of MC. MC was induced as described by Chan et al. ${ }^{17}$ HCT116 $14-3-3 \sigma^{-/-}$cells were treated for up to $72 \mathrm{~h}$ with $0.2 \mu \mathrm{g} / \mathrm{ml}$ Dox, photographed, harvested, and subjected to cytogenetic preparation and analysis at the indicated intervals.

Abrogation of $\mathrm{G}_{2}$ checkpoint by UCN-01 treatment. HCT116 cells were treated concurrently with $1 \mu \mathrm{g} / \mathrm{ml}$ Dox and $300 \mathrm{nM} \mathrm{UCN}-01$ (Sigma-Aldrich) for $6 \mathrm{~h}$.

Normoxic treatment. HCT116 cells were grown in a hypoxic chamber with $3.5 \% \mathrm{O}_{2}$ and $5 \% \mathrm{CO}_{2}$, and acclimatized for 5 days until cells were actively dividing. The cells were then pretreated for $3 \mathrm{~h}$ with colcemid, a mitotic shake-off was performed, and the cells were treated for 6 or $12 \mathrm{~h}$ with $1 \mu \mathrm{g} / \mathrm{ml}$ Dox under colcemid pressure.

Temperature shift. COLO- 357 cells were cultured at $37^{\circ} \mathrm{C}$ and then cultured at $42^{\circ} \mathrm{C}$ for 10 days at which time cells stabilized and began to grow again. The cells were then transferred back to $37^{\circ} \mathrm{C}$ and harvested at the indicated time points (Figures 3a and b).

Linking C-Frag and genomic instability. MDAH-041 and MOSEC cells were harvested during different time periods where the population showed genome stability and instability as determined by spectral karyotyping (SKY), and prepared for cytogenomic evaluation. ${ }^{11,13}$

Induction of pathway-defined stress. COLO-357 cells were treated three independent times for 4, 8, and $24 \mathrm{~h}$ with the ER stress inducers A23187, DTT, TG, and TM (Sigma-Aldrich).

Centrosome amplification. Cells were attached to glass slides using a Shandon Cytospin at 1000 r.p.m. for $5 \mathrm{~min}$, fixed for $7 \mathrm{~min}$ in 1\% paraformaldehyde, permeabilized with $0.1 \%$ Triton X-100, incubated with a $\gamma$-tubulin antibody (Abcam, Cambridge, MA, USA), washed, incubated with an Alexa-Fluor-488-labeled antimouse antibody (Invitrogen, Carlsbad, CA, USA), washed, coverslipped with DAPI and anti-fade (Invitrogen), and imaged.

Inhibition of HSP90. HCT116 cells were treated for a total of $54 \mathrm{~h}$ with Dox $(50 \mathrm{nM}, 150 \mathrm{nM}, 1 \mu \mathrm{M}$, or $1 \mu \mathrm{g} / \mathrm{ml})$; after $24 \mathrm{~h}$ of treatment, $100 \mathrm{nM}$ 17-DMAG (LC Laboratories, Woburn, MA, USA) was added to the cells. Following a 24-h incubation of 17-DMAG and Dox, $1 \times$ colcemid was added for $6 \mathrm{~h}$ prior to harvest.

Proteasomal activity assay. Proteosomal activity was measured as previously described. ${ }^{33}$ Cells were washed 3 times with ice-cold PBS and scraped

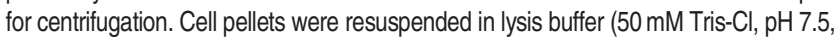
$10 \mathrm{mM} \mathrm{MgCl}_{2}, 100 \mathrm{mM} \mathrm{KCl}, 1 \%$ Triton X-100, 10\% glycerol, $1 \mathrm{mM} \mathrm{DTT,} 1 \mathrm{X}$ protease inhibitor cocktail) and mixed with rotation at $4^{\circ} \mathrm{C}$ for $2 \mathrm{~h}$. Extract was centrifuged at $13200 \mathrm{rpm}$ for $10 \mathrm{~min}$ at $4^{\circ} \mathrm{C}$. Protein concentration was determined using Bradford Assay Kit (Bio-Rad, Hercules, CA, USA). Chymotrypsin-like activity of the $20 \mathrm{~S}$ proteasome was measured by incubation of $40 \mu \mathrm{M}$ Suc-Leu-Leu-Val-Tyr-AMC (Boston BioChem, Cambridge, MA, USA) with $20 \mu \mathrm{g}$ cell extract in $100 \mu$ lassay buffer ( $50 \mathrm{mM}$ Tris-Cl, pH 7.5) at $37^{\circ} \mathrm{C}$ for $1 \mathrm{~h}$. The released fluorescence signals were monitored with an excitation filter of $355 \mathrm{~nm}$ and an emission filter of $460 \mathrm{~nm}$ using VersaFluot Fluorometer (Bio-Rad).

Differential induction of apoptosis and C-Frag. HCT116 cells were treated for 6 and $12 \mathrm{~h}$ with $1 \mu \mathrm{g} / \mathrm{ml}$ Dox (MP Biochemicals, Solon, OH, USA), $1 \mu \mathrm{M}$ docetaxel (MP Biochemicals), $10 \mu \mathrm{M}$ docetaxel, and 1 or $10 \mu \mathrm{M}$ docetaxel combined with $1 \mu \mathrm{g} / \mathrm{ml}$ Dox.
Statistical analysis. Paired t-tests were performed using Microsoft Excel.

\section{Conflict of Interest}

The authors declare no conflict of interest

Acknowledgements. This manuscript is part of a series of studies entitled 'The mechanism of somatic and organismal evolution'. We thank Dr. Bert Vogelstein for the HCT116 and HCT116 14-3-3 ${ }^{-l-}$ cell lines, Dr. Yi Sun for the H1299-v138 cell line, and Dr. Anton Goustin for the COLO-357 cell line. This work was partially supported by grants to HHQH from the Komen Foundation, SeeDNA Inc., and the US Department of Defense (GW093028); and grants to KZ by the US Department of Defense (BC095179P1). JBS was supported by a WSU CMMG post-doctoral fellowship. We also thank Drs. Alex Gow and James Tucker for valuable discussion.

1. Heng HH, Stevens JB, Bremer SW, Ye KJ, Liu G, Ye CJ. The evolutionary mechanism of cancer. J Cell Biochem 2010; 109: 1072-1084.

2. Negrini S, Gorgoulis VG, Halazonetis TD. Genomic instability - an evolving hallmark of cancer. Nat Rev Mol Cell Biol 2010; 11: 220-228.

3. Tabas I, Ron D. Integrating the mechanisms of apoptosis induced by endoplasmic reticulum stress. Nat Cell Biol 2011; 13: 184-190.

4. Brown JM, Wouters BG. Apoptosis, p53, and tumor cell sensitivity to anticancer agents Cancer Res 1999; 59: 1391-1399.

5. Park SS, Kim MA, Eom Y-W, Choi KS. Bcl-xL blocks high dose doxorubicin-induced apoptosis but not low dose doxorubicin-induced cell death through mitotic catastrophe. Biochem Biophys Res Commun 2007; 363: 1044-1049.

6. Blagosklonny MV. Apoptosis, proliferation, differentiation: in search of the order. Semin Cancer Biol 2003; 13: 97-105.

7. Kondo S. Altruistic cell death: mitotic catastrophe model of apoptosis. Protein Nucleic Acid Enzyme 1994; 39: 2238-2245.

8. Roninson IB, Broude EV, Chang BD. If not apoptosis, then what? - Treatment-induced senescence and mitotic catastrophe in tumor cells. Drug Resist Updat 2001; 4: 303-313.

9. Stevens JB, Liu G, Bremer SW, Ye KJ, Xu W, Xu J et al. Mitotic cell death by chromosome fragmentation. Cancer Res 2007; 67: 7686-7694.

10. Castedo M, Perfettini JL, Roumier T, Kroemer G. Cyclin-dependent kinase-1: linking apoptosis to cell cycle and mitotic catastrophe. Cell Death Differ 2002; 9: 1287-1293.

11. Heng HH, Stevens JB, Liu G, Bremer SW, Ye KJ, Reddy PV et al. Stochastic cancer progression driven by non-clonal chromosome aberrations. J Cell Physiol 2006; 208: 461-472.

12. Heng HH, Bremer SW, Stevens JB, Ye KJ, Liu G, Ye CJ. Genetic and epigenetic heterogeneity in cancer: a genome-centric perspective. J Cell Physiol 2009; 220: 538-547.

13. Ye CJ, Stevens JB, Liu G, Bremer SW, Jaiswal AS, Ye KJ et al. Genome based cell population heterogeneity promotes tumorigenicity: the evolutionary mechanism of cancer. J Cell Physiol 2009; 219: 288-300.

14. Berger MF, Lawrence MS, Demichelis F, Drier Y, Cibulskis K, Sivachenko AY et al. The genomic complexity of primary human prostate cancer. Nature 2011; 470: 214-220.

15. Stephens PJ, Greenman CD, Fu B, Yang F, Bignell GR, Mudie LJ et al. Massive genomic rearrangement acquired in a single catastrophic event during cancer development. Cell 2011; 144: 27-40.

16. Borst $\mathrm{P}$, Rottenberg $\mathrm{S}$. Cancer cell death by programmed necrosis? Drug Resist Updat 2004; 7 : 321-324.

17. Chan TA, Hermeking $H$, Lengauer $C$, Kinzler KW, Vogelstein B. 14-3-3 $\sigma$ is required to prevent mitotic catastrophe after DNA damage. Nature 1999; 401: 616-620.

18. Tse AN, Schwartz GK. Potentiation of cytotoxicity of topoisomerase I poison by concurrent and sequential treatment with the checkpoint inhibitor UCN-01 involves disparate mechanisms resulting in either p53-independent clonogenic suppression or p53-dependent mitotic catastrophe. Cancer Res 2004; 64: 6635-6644.

19. Heng $\mathrm{HH}$. The genome-centric concept: resynthesis of evolutionary theory. Bioessays 2009; 31: 512-525.

20. Stevens JB, Abdallah BY, Regan SM, Liu G, Bremer SW, Ye CJ et al. Comparison of mitotic cell death by chromosome fragmentation to premature chromosome condensation. Mol Cytogenet 2010; 3: 20.

21. Massabuau JC. From low arterial- to low tissue-oxygenation strategy. An evolutionary theory. Respir Physiol 2001; 128: 249-261.

22. Zhang K, Kaufman RJ. From endoplasmic-reticulum stress to the inflammatory response Nature 2008; 454: 455-462.

23. Taylor BF, McNeely SC, Miller HL, States JC. Arsenite-induced mitotic death involves stress response and is independent of tubulin polymerization. Toxicol Appl Pharmacol 2008; 230: 235-246

24. Shen K, Wang Y, Brooks S, Raz A, Wang YA. ATM is activated by mitotic stress and suppresses centrosome amplification in primary but not in tumor cells. J Cell Biochem 2006; 99: 1267-1274. 
25. Lange BMH, Bachi A, Wilm M, Gonzalez C. Hsp90 is a core centrosomal component and is required at different stages of the centrosome cycle in Drosophila and vertebrates. EMBO 2000; 19: 1252-1262.

26. Janssen A, Kops GJPL, Medema RH. Elevating the frequency of chromosome mis-segregation as a strategy to kill tumor cells. Proc Natl Acad Sci USA 2009; 106 19108-19113.

27. Korolchuk VI, Menzies FM, Rubinsztein DC. Mechanisms of cross-talk between the ubiquitin-proteasome and autophagy-lysosome systems. FEBS Lett 2010; 584: 1393-1398.

28. Brown EJ, Baltimore D. ATR disruption leads to chromosomal fragmentation and early embryonic lethality. Genes Dev 2000; 14: 397-402.

29. Fukasawa K, Wiener F, VandeWoude GF, Mai SB. Genomic instability and apoptosis are frequent in p53 deficient young mice. Oncogene 1997; 15: 1295-1302.

30. Hübner B, Strickfaden H, Müller S, Cremer M, Cremer T. Chromosome shattering: a mitotic catastrophe due to chromosome condensation failure. Eur Biophys J 2009; 38: 729-747.

31. Taylor BF, McNeely SC, Miller HL, Lehmann GM, McCabe Jr MJ, States JC. p53 suppression of arsenite-induced mitotic catastrophe is mediated by p21CIP1/WAF1. J Pharmacol Exp Ther 2006; 318: 142-151.

32. Godinho S, Kwon M, Pellman D. Centrosomes and cancer: how cancer cells divide with too many centrosomes. Cancer Metastasis Rev 2009; 28: 85-98.

33. Xu H, Ju D, Jarois T, Xie Y. Diminished feedback regulation of proteasome expression and resistance to proteasome inhibitors in breast cancer cells. Breast Cancer Res Treat 2008; 107: 267-274.

34. Kroemer G, El-Deiry WS, Golstein P, Peter ME, Vaux D, Vandenabeele P et al. Classification of cell death: recommendations of the Nomenclature Committee on Cell Death. Cell Death Differ 2005; 12 (S2): 1463-1467.
35. Carmona-Gutierrez D, Eisenberg T, Büttner S, Meisinger C, Kroemer G, Madeo F Apoptosis in yeast: triggers, pathways, subroutines. Cell Death Differ 2010; 17: 763-773.

36. Niikura $\mathrm{Y}$, Ogi $\mathrm{H}$, Kikuchi $\mathrm{K}$, Kitagawa K. BUB3 that dissociates from BUB1 activates caspase-independent mitotic death (CIMD). Cell Death Differ 2010; 17: 1011-1024.

37. O'Sullivan-Coyne G, O'Sullivan GC, O'Donovan TR, Piwocka K, McKenna SL. Curcumin induces apoptosis-independent death in oesophageal cancer cells. Br J Cancer 2009; 101: 1585-1595.

38. Heng HH, Liu G, Stevens JB, Bremer SW, Ye KJ, Abdallah BY et al. Decoding the genome beyond sequencing: the new phase of genomic research. Genomics 2011; doi:10.1016/ j.ygeno.2011.05.008 (in press).

39. Xu J, Zhou J-Y, Tainsky MA, Wu GS. Evidence that tumor necrosis factor-related apoptosis-inducing ligand induction by 5 -aza-2'-deoxycytidine sensitizes human breast cancer cells to adriamycin. Cancer Res 2007; 67: 1203-1211.

40. Schlegel R, Pardee AB. Caffeine-induced uncoupling of mitosis from the completion of DNA replication in mammalian cells. Science 1986; 232: 1264-1266.

41. Nichols WW, Levan A. Measles associated chromosome breakage. Archiv fèur die gesamte Virusforschung 1965; 16: 168-174.

Cell Death and Disease is an open-access journal published by Nature Publishing Group. This work is licensed under the Creative Commons Attribution-Noncommercial-No Derivative Works 3.0 Unported License. To view a copy of this license, visit http://creativecommons.org/licenses/by-nc-nd/3.0/

Supplementary Information accompanies the paper on Cell Death and Disease website (http://www.nature.com/cddis) 